\title{
Transiciones sistemáticas de cobertura de suelo en la Región Costa Maya, Quintana Roo, México, 1993 2010 ${ }^{1}$
}

\author{
Systematic Land Cover Transitions in the Costa Maya Region, \\ Quintana Roo, México, 1993 2010
}

Para citar este artículo, utilice el nombre completo así:

Simbangala, M., Campos, B. L. \& Arriaga, J. C. (2015). Transiciones sistemáticas de cobertura de suelo en la Región Costa Maya, Quintana Roo, México, 1993-2010. Perspectiva Geográfica, 20(1), 103-132.

\section{Resumen}

La Región Costa Maya (RCM) experimenta cambios significativos en el paisaje, debido a las actividades humanas que amenazan su sostenibilidad.

1 Este artículo hace parte de la tesis doctoral: "Cambios en el paisaje en la Costa Maya", del Doctorado en Geografía de la Universidad de Quintana Roo, realizado con la Beca de la Secretaría de Relaciones Exteriores del Gobierno de México para Extranjeros.

2 Candidato a Doctor en Geografía de la Universidad de Quintana Roo, Maestro en Ciencias de la Tierra de la Universidad de Colima, México.simbamx@gmail.com

3 Doctora en Geografía de la Universidad Nacional Autónoma de México, Profesora-Investigadora en la Universidad de Quintana Roo, Coordinadora del Centro de Innovación y Desarrollo del Turismo de la Universidad de Quintana Roo, México. bonniecamposcamara@gmail.com

4 Doctor en Historia Moderna del Instituto Estudios Históricos José María Luis Mora, Profesor-Investigador de la Universidad de Quintana Roo, Secretario Técnico de Investigación y Posgrado de la División de Ciencias Políticas y Humanidades de la Universidad de Quintana Roo, México. arriaga@uqroo.edu.mx 
Se aplicó un análisis utilizando tres mapas clasificados, un SIG y un análisis más detallado de la matriz de transición entre 1993-2010. Las tendencias, en las transiciones del paisaje, son: áreas de cultivo a zona urbana; intercambios entre áreas de cultivo y selva; y manglar popal tular. Las tendencias que se manifestaron fueron: la disminución de la actividad agrícola, en comparación con las actividades de la economía del turismo, la cual presenta un crecimiento rápido que se ve reflejado en la expansión urbana; síntoma de la ausencia de un crecimiento económico equilibrado. El estudio revela nuevas perspectivas sobre la naturaleza y los procesos (tanto aleatorios, como sistemáticos) y se identificó señales dominantes en los cambios de coberturas del suelo, que facilitarían planificación de la gestión sostenible de recursos naturales.

Palabras clave: cambios en el paisaje, Costa Maya, intercambio, matriz, persistencia, transición.

\section{Abstract}

The Costa Maya Region (CMR) is experiencing rapid land cover changes due to human activities threatening its sustainability. We applied a novel change detection analysis based on three classified maps and an in-depth statistical analysis to obtain a better understanding of key inter-category transitions and processes behind these transitions, from 1993-2010. The dominant signals of transition in the CMR are: agricultural land to urban area; exchanges between agricultural land and rainforest; and between mangroves and hydrophytic plants. The signals are characterized by a declining agricultural sector compared to rapidly expanding tourism activities reflected in urban sprawl, which implies a lack of balanced economic growth in the CMR. The study has revealed some new insights into the nature and processes (either random or systematic) of land cover change, enabling us to identify the dominant signs of land cover transitions, which should facilitate improved management of natural resources.

Keywords: Land Cover Change, Costa Maya, Matrix, Persistence, Swap, Transition 


\section{Introducción}

La Región Costa Maya (RCM) es un área de la costa sur del Estado de Quintana Roo, en donde han sido instalados numerosos negocios del ramo turístico. El nombre de esta región fue asignado, en 1991, por el gobierno de Quintana Roo, como una marca turística que sirviera para promover el desarrollo económico del sur del estado (Campos-Cámara, 2010). El impulso a la actividad turística en la RCM ha estimulado el crecimiento acelerado de infraestructura (carretera, caminos, el muelle de cruceros, etcétera) y de las manchas urbanas (Díaz-Gallegos \& Acosta-Velázquez, 2009; Hirales-Cota, et al., 2010). Asimismo, la actividad turística ha convertido a la RCM en un importante enclave económico de Quintana Roo, y en uno de los principales generadores de ingresos, empleo y comercio en el sur del estado (Campos-Cámara, 2010).

En la RCM es evidente el impacto ambiental, generado por el crecimiento urbano y por las actividades sociales, asociadas a la economía del turismo (Castillo-Villanueva, 2007; Campos-Cámara, 2010), pues se trata de un área geográfica con un ecosistema frágil (PNUMA, 1996). En la zona marina, por ejemplo, está la segunda barrera arrecifal coralina en el mundo (después de la gran baerrera australiana); en la zona terrestre existen numerosos estuarios, aguadas y lagunas en donde habitan numerosas especies animales y vegetales sensibles a la explotación humana (Velázquez-Torres \& Castillo-Villanueva, 2007). El impacto ambiental se ha incrementado, debido a la expansión agrícola sobre suelos marginales; el crecimiento urbano descontrolado y sin servicios, la deforestación de las áreas de manglar y de selva baja, y la destrucción de los hábitat animal, debido a la eliminación selectiva de la vegetación nativa (Velázquez-Torres \& Castillo-Villanueva, 2007; Vázquez-Trejo, 2010).

Aunque existen programas de ordenamiento ecológico territorial (POET) para la RCM, en los que se visualiza la restauración, protección, conservación y aprovechamiento racional de los recursos naturales, y en los que, además, se impone reglas al desarrollo económico, turístico y urbano, lo cierto es que los programas de desarrollo urbano y los planes de manejo de las áreas protegidas no han frenado la amenaza ambiental sobre la región (Rosado-May \& Kissmann, 
1998; González-Vera, 2010; Vázquez-Trejo, 2010).

Este artículo pretende demostrar la afirmación anterior mediante un análisis del cambio en el paisaje. En concordancia con Olson, et al. (2004), se considera que este tipo de análisis es una herramienta especialmente útil para realizar investigaciones de tipo ambiental, ya que brinda información abundante. El análisis del cambio ofrece oportunidades únicas para monitorear el paisaje que se refleja en un gran número de estudios (Petit, et al., 2000; Lambin, et al., 2006; Díaz-Gallegos, et al., 2010). El corazón de esta técnica es la comparación de mapas de la misma cobertura terrestre, obtenidos de imágenes satelitales en tiempos diferentes (Lambin, et al., 2003; Mas, et al., 2012). Con base en esos datos se construye una matriz de tabulación cruzada, con la cual se pueden caracterizar, cuantitativamente, los procesos de cambio ocurridos en el paisaje para determinados cortes de tiempo.

Para llevar a cabo lo anterior, primero se caracteriza cuantitativamente la cobertura del suelo en la RCM, mediante la matriz de transición tradicional. Enseguida, se aplica la técnica del análisis pro- puesta por Pontius Jr., et al, (2004) y extendida por Braimoh (2006) para detectar transiciones sistemáticas y señales dominantes de cambios en el paisaje, durante dos períodos de tiempo (1993 a 2000 y 2000 a 2010).

\section{Área del estudio}

La RCM se encuentra en la parte sur oriental de la península de Yucatán, en la costa sur del estado de Quintana Roo, en el municipio de Othón P. Blanco, entre las coordinadas geográficas $19^{\circ} 05 \mathrm{~N}, 87^{\circ} 35 \mathrm{~W}$ y $18^{\circ}$ $10 \mathrm{~N} 87^{\circ} 33 \mathrm{~W}$. Está delimitada al este por el Mar Caribe, al norte con la Reserva de la Biosfera de Sian Káan, al oeste con la laguna de Bacalar y al sur con Belice. El terreno es generalmente plano, con una altura promedio de $8 \mathrm{~m}$ sobre el nivel de mar. El suelo está clasificado por la FAO/Unesco (1988) en los siguientes tipos: Regosoles cacaricos, Rendzinas-Litosoles y Solonchac-órtico (esos tipos de suelo corresponden, en la terminología Maya, a: Huntunich, Tsek'el y Ak'alche, respectivamente) (Díaz-Gallegos \& Acosta-Velázquez, 2009).

En la RCM prevalece el clima tropical cálido subhúmedo con régimen de lluvias en verano. La tem- 
peratura media anual es de $27^{\circ} \mathrm{C}$, La franja costera se caracteriza por con temperatura máxima de $40^{\circ} \mathrm{C}$ tener manglares y marismas que y mínima de $14^{\circ} \mathrm{C}$, y precipitación abarcan grandes áreas pantanosas promedio anual de $1249 \mathrm{~mm}$. La y cenagosas. El ecosistema marino temporada más lluviosa compren- está integrado a la barrera arrecifal de los meses de mayo a octubre. mesoamericana.

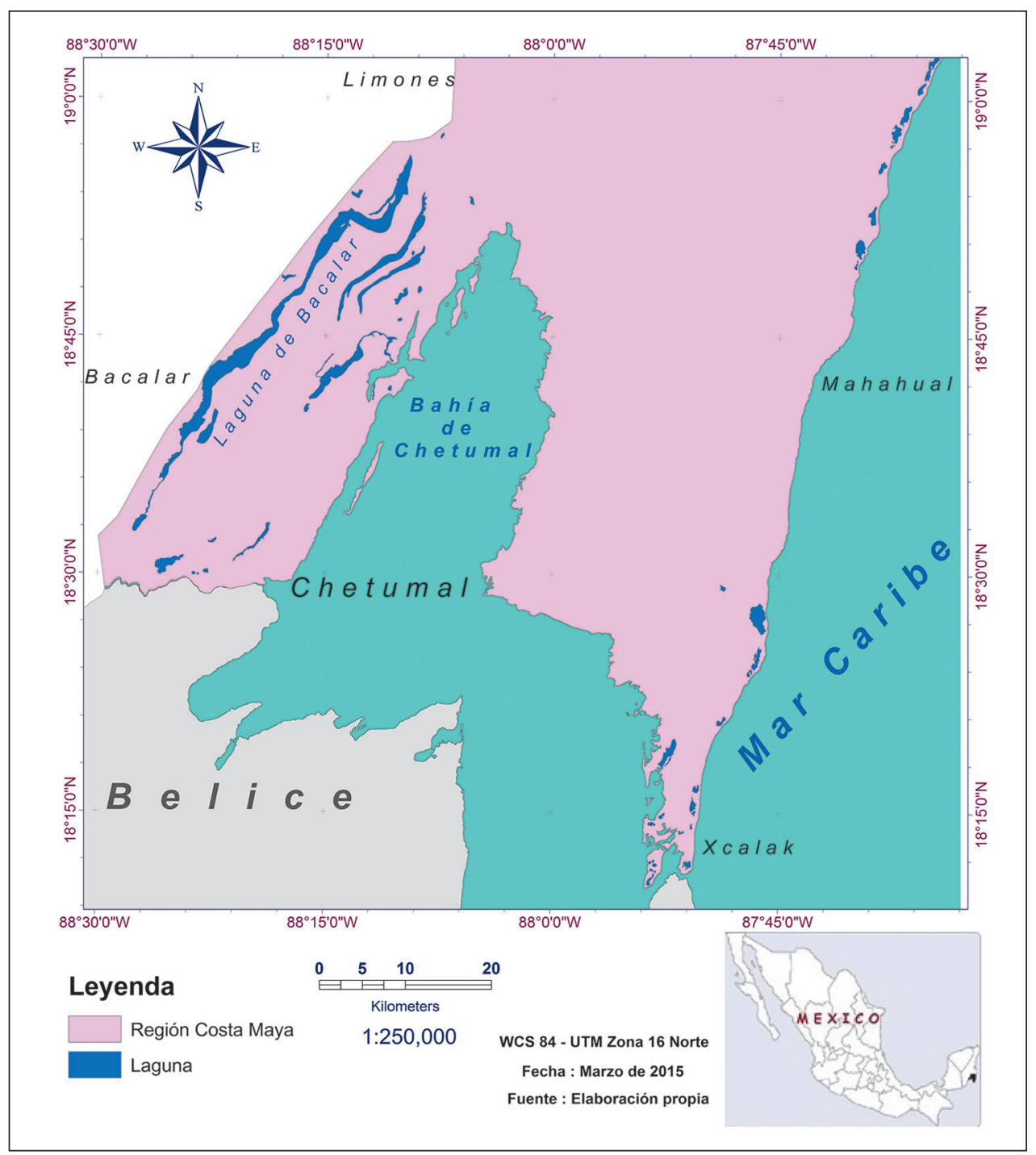

Figura 1. Ubicación de la Región Costa Maya (RCM)

Fuente: Elaboración propia, con base en datos del Landsat TM. 
Chetumal es la cabecera municipal, capital del Estado y concentra la mayor población de toda la RCM. Las actividades económicas principales en la RCM son: el turismo, la pesca, la agricultura, la ganadería y la extracción forestal.

\section{Metodología e instrumentos de evaluación}

La tabulación cruzada es una herramienta poderosa en el análisis espacio-temporal, utilizada, frecuentemente, en diagnósticos rápidos de condición de recursos naturales (Pontius Jr \& Cheuk, 2006); sus productos son considerados de gran utilidad para apoyar políticas encaminadas a disminuir o revertir el deterioro ambiental (Pontius Jr, et al., 2004; Manandhar, et al., 2010). En México, el procedimiento ha sido ampliamente utilizado en varios estudios de cambios en el paisaje, por ejemplo, para la evaluación del cambio en el uso/ cobertura del suelo (Mas, et al., 2004); análisis del proceso de deforestación (Díaz-Gallegos, et al., 2010; Hirales-Cota, et al., 2010); de procesos hidrológicos (Mendoza, et al., 2010) y de urbanización (López, et al., 2001; Valdez-Lazalde, et al., 2011; Díaz, et al., 2014).
Por su parte, el análisis tradicional de matrices ha sido criticado severamente en estudios recientes (Pontius Jr, et al., 2004; Versace, et al., 2008; Teferi, et al., 2013). Este análisis provee información sobre los cambios más prominentes en el paisaje; sin embargo, falla en su evaluación, debido a que los métodos estadísticos comúnmente usados para interpretar los datos carecen de conceptos fundamentales para extraer el máximo contenido de la información que pueda ofrecer una matriz de tabulación cruzada (Pontius Jr, et al., 2004), ya que solo calcula la cantidad y ubicación de los tipos de cambio y pasa por alto, o no siempre detecta, las transiciones aleatorias y sistemáticas que pueden tener una influencia importante en la condición y el funcionamiento del paisaje (Versace, et al., 2008).

Las transiciones aleatorias son aquellas influenciadas por los procesos fortuitos o de cambios únicos; dichas transiciones están en función de la proporción de la cobertura del suelo (Braimoh, 2006). Generalmente, son causadas por la interacción de factores de uso del suelo que actúan abruptamente, como la migración espontánea, los conflictos internos, los cambios 
en las condiciones macroeconómicas, la pérdida de los derechos a la tierra, los recursos, u otros factores de producción. Por su parte, las transiciones sistemáticas son aquellas debidas a procesos regulares o comunes de cambio. Estos procesos tienden a evolucionar de una manera más consistente o progresiva dictados, principalmente, por factores socioeconómicos, tales como: crecimiento demográfico, expansión urbana, falta de educación pública sobre el medio ambiente o cambios en las políticas de gestión del suelo (Lambin, et al., 2003).

Desde una perspectiva estadística, las transiciones aleatorias se producen cuando una cobertura terrestre sustituye a otro tipo en proporción con el tamaño de dicha categoría. Las ganancias o pérdidas no aleatorias implican un proceso sistemático de cambio en el que una cobertura terrestre se dirige, sistemáticamente, a otras coberturas para reemplazarlas (Pontius Jr., et al., 2004).

La identificación de las transiciones sistemáticas permite a los investigadores centrarse en las señales más fuertes de cambios en el paisaje y ayuda a vincular patrones de cambios de paisaje a los procesos (Manandhar, et al., 2010). Es importante entender si el proceso detrás de una transición es aleatorio o sistemático, ya que la política para mantener la sustentabilidad ambiental debe ser orientada a revertir procesos sistemáticos. El método propuesto por Pontius Jr. (2004) permite comprobar si las transiciones entre categorías observadas han sido impulsadas por procesos sistemáticos o aleatorios. Ese método se apoya en el cálculo de diversos componentes (ganancia, pérdida, intercambio y cambio neto) de una matriz de tabulación cruzada estándar. Teixeira, Heliana \& Marques (2014), proporcionan un excelente resumen de su gama de aplicaciones.

\section{Instrumentos cartográficos}

Se utilizó tres mapas de cobertura terrestre (Figura 2) derivados, anteriormente, de datos de Landsat $\mathrm{TM} / \mathrm{ETM}+$ a partir de clasificación orientada sobre los segmentos para los años 1993, 2000 y 2010. Estos mapas ilustran información de seis amplias categorías: agua, zona urbana, zonas de cultivo, zonas de popal-tular (P. Tular), zonas de manglar y área selvática. La evaluación de error del mapa de 2000 , 
para el que existen datos de refe- II,), presentó una exactitud global rencia fiables (mapa INEGI, serie del 94\% (valor de $\boldsymbol{\kappa}=0.914$ ).

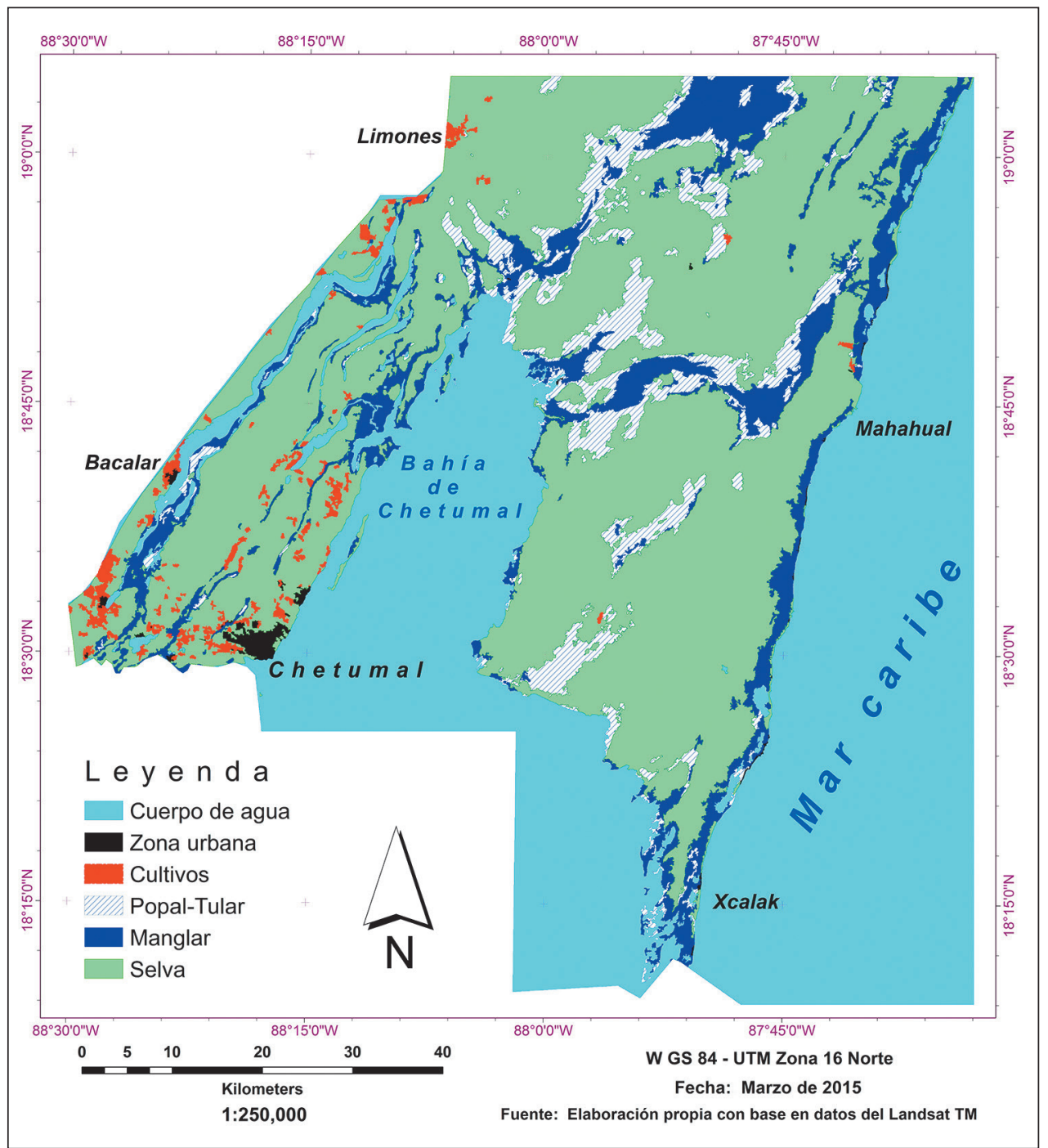




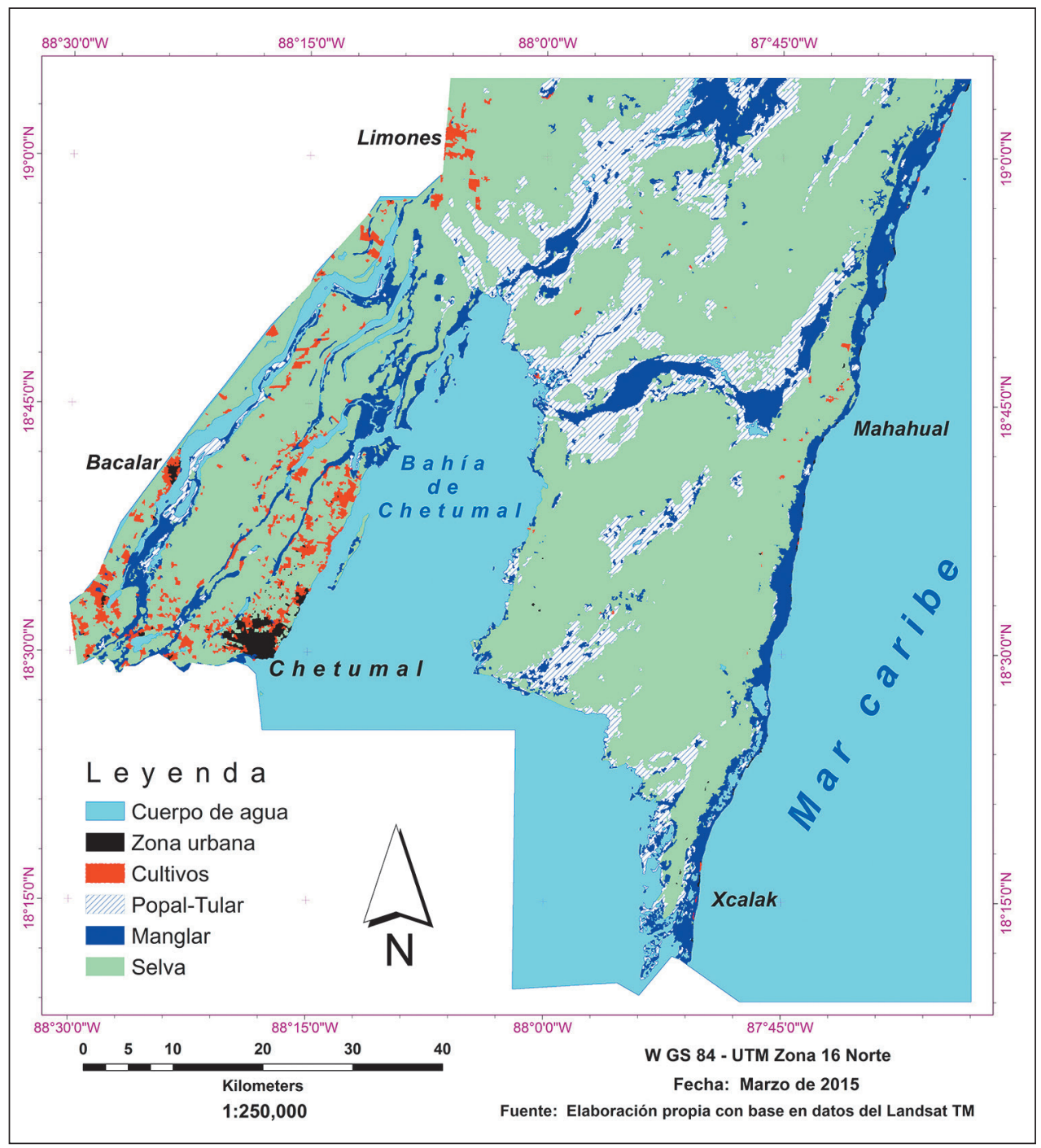




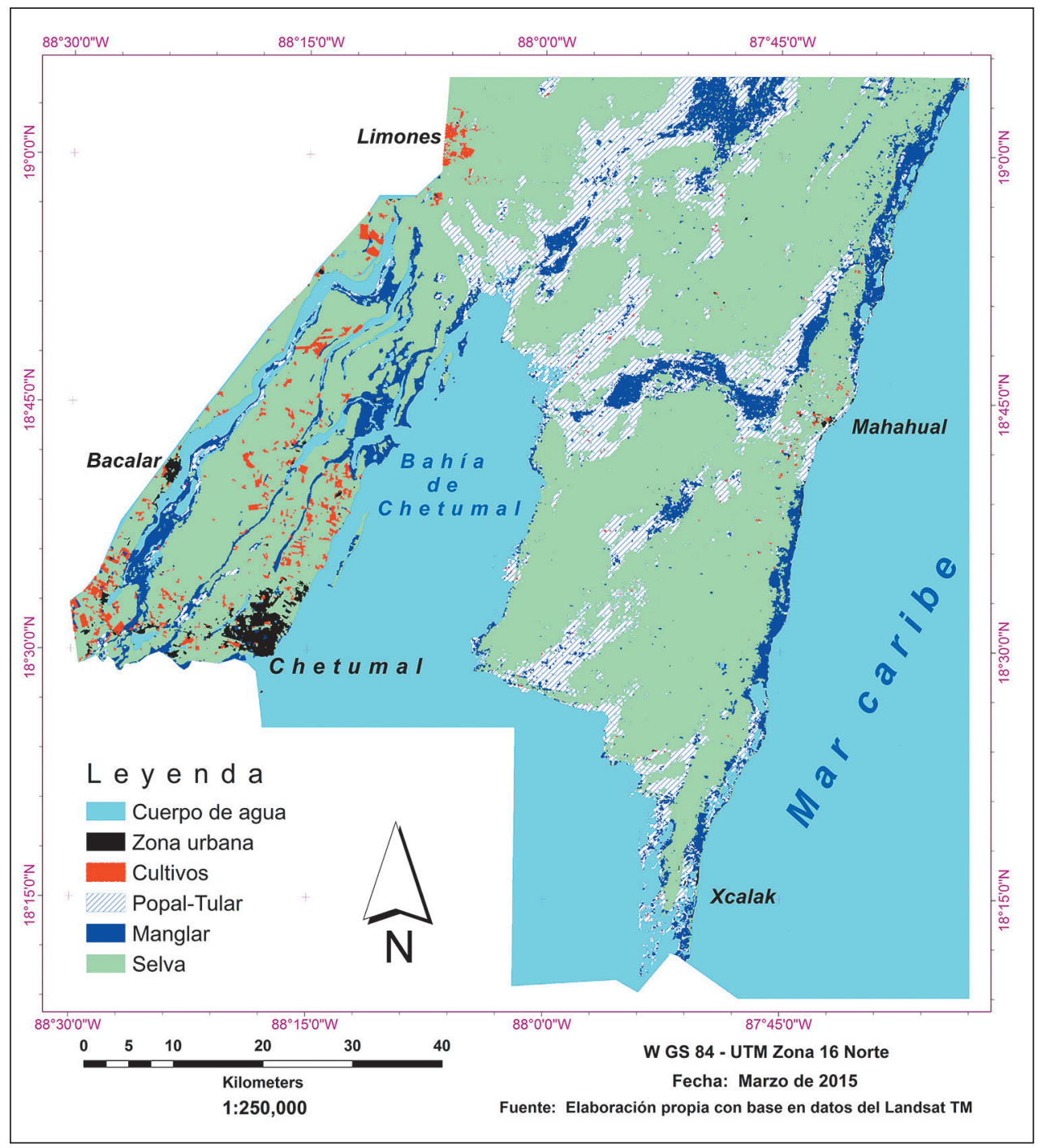

Figura 2. Mapas de cobertura del suelo en la RCM para 1993, 2000 y 2010.

Fuente: Elaboración propia.

Detección de los cambios en la 2000-2010. Para ello, se utilizó el cobertura terrestre

CROSSTAB, una herramienta de Idrisi selva; básicamente, una su-

Se aplicó la técnica de postclasifi- perposición de dos imágenes precación para analizar los cambios, viamente clasificadas en un SIG, durante períodos 1993-2000 y que permite identificar las transi- 
ciones de una cobertura terrestre a otra (Warner \& Campagna, 2009). Con CROSSTAB, se generó dos matrices de transición (Tablas 2 y 3 ), en donde las entradas fuera de la diagonal comprenden las proporciones del paisaje que experimentaron la transición de una categoría a otra categoría, mientras que las entradas en la diagonal indican persistencia de categorías. Las entradas en las filas y columnas representan las categorías en el tiempo $\mathrm{T}_{1}$ (origen), y el tiempo $\mathrm{T}_{2}$ (destino), respectivamente. Los valores totales de las filas de la derecha y de las columnas en la parte inferior, indican la proporción del paisaje por categoría en $\mathrm{T}_{1}$ y $\mathrm{T}_{2}$, respectivamente. Después, se sometió las dos matrices a un análisis más detallado para detectar transición sistemática.

\section{Detección de las transiciones inter-categóricas}

Para detectar la transición sistemática, las dos matrices de transición fueron analizadas en cuatro pasos, acorde con la metodología de Pontius Jr. (2004) para derivar los siguientes componentes del cambio por categorías: la ganancia $\mathrm{y}$ pérdida en cada tipo de cobertura, intercambio, cambio neto, las ga- nancias y pérdidas esperadas, ganancia y pérdida inter-categóricas. Este enfoque distingue patrones importantes del cambio del paisaje distintos del alto nivel de persistencia común en la mayoría de otras investigaciones.

\section{a) Ganancia, pérdida, persisten- cia y vulnerabilidad a la transi- ción}

La ganancia se refiere a un aumento del área de una cobertura terrestre, mientras que la pérdida se refiere a una disminución de la superficie de una cobertura terrestre entre dos puntos de tiempo. Se derivó la ganancia de cada categoría, de la matriz de tabulación cruzada extendida, restando la persistencia de la columna total de la matriz; después, se calculó la pérdida restando la persistencia del total de la fila. Se derivó las proporciones: pérdidas-a-persistencia (pérdida/ persistencia); ganar-a-persistencia (ganancia/persistencia) para evaluar la vulnerabilidad de cada categoría por perder o ganar mediante un enfoque desarrollado por Braimoh (2006). Valores superiores a uno indican una mayor tendencia de una clase a cambiar a otras categorías que a persistir. Del mismo modo, los valores de relación ga- 
nar-persistencia $\left(\mathbf{g}_{\mathbf{p}}\right)$, mayor que uno indican más ganancia que la persistencia.

\section{b) Intercambio y cambio neto}

El intercambio es el cambio de ubicación de un tipo de cobertura terrestre entre dos puntos de tiempo; se lo derivó de la ganancia bruta y pérdida bruta (Pontius Jr., et al., 2004; Versace, et al., 2008) entre 1993-2000 y 2000-2010. El concepto de intercambio da más sentido a la interpretación de una situación en la que el cambio neto, en un tipo de cobertura terrestre, es cero y evita la tendencia a interpretar la situación como ausencia de cambio. Según Pontius Jr. (2004), la falta de cambio neto no indica necesariamente una ausencia de cambio en el paisaje, ya que el cambio neto no logra captar el componente intercambio de cambio. El intercambio de una categoría es el cambio total menos la variación neta en dicha categoría. El cambio neto es la diferencia en área de una cobertura terrestre entre dos puntos de tiempo o el valor absoluto de la diferencia entre la ganancia y la pérdida. Como Pontius Jr. (2004) señala, el cambio neto subestima el cambio total en el paisaje, ya que no toma en cuenta el cambio en la ubicación, como lo hace el intercambio.

\section{c) Transiciones aleatorias y siste- máticas}

Se utilizó los métodos descritos en Pontius Jr. (2004), para realizar un análisis más detallado de las pérdidas, ganancias y persistencia para determinar si las transiciones eran de carácter aleatorio o sistemático. En primer lugar, se calculó la ganancia esperada de cada categoría mediante la distribución de la ganancia observada entre las otras clases, con base en sus proporciones relativas en $\mathrm{T}_{1}$ (Ecuación 1). Del mismo modo, se determinó las pérdidas esperadas mediante la distribución de las pérdidas observadas entre las otras clases, con base en sus proporciones relativas en $\mathrm{T}_{1}$ (Ecuación 2).

Las ecuaciones ( $1 \quad y \quad$ y $)$, respectivamente, dan como resultado transiciones esperadas bajo un proceso aleatorio de ganancia (o pérdida), en donde todas las variables son expresadas porcentaje del área de estudio (Pontius Jr., et al., 2004). 


$$
\begin{gathered}
G_{i j}=\left(P_{+j}-P_{i j}\right)\left(\frac{P_{i+}}{100-P_{j+}}\right), \quad \forall i \neq j \\
L_{i j}=\left(P_{i+}-P_{i i}\right)\left(\frac{P_{+j}}{100-P_{+i}}\right), \quad \forall i \neq j
\end{gathered}
$$

En donde $\mathrm{G}_{\mathrm{ij}}$ es la transición esperada desde la categoría i a la categoría $\mathrm{j}$, debido a un proceso de ganancia al azar. $\left(\mathrm{P}_{+\mathrm{j}}-\mathrm{P}_{\mathrm{jj}}\right)$ es la ganancia neta total de la categoría j entre 1993-2000 y 2000-2010. $\mathrm{P}_{\mathrm{i}+}$ es el tamaño de la categoría

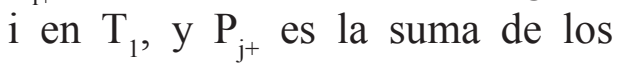
tamaños de todas las categorías, excepto j en $T_{1}$. Para la ecuación 2 , $\mathrm{L}_{\mathrm{ij}}$ es la transición esperada entre categorías i a la categoría $\mathrm{j}$, debido a un proceso al azar de pérdida. $\mathrm{P}_{\mathrm{i}+}$ - $\mathrm{P}_{\mathrm{ii}}$ es la pérdida neta total de la categoría $\mathrm{i}$ entre $\mathrm{T}_{1} \mathrm{y} \mathrm{T}_{2}, \mathrm{P}_{\mathrm{i}+}$ es el tamaño de la categoría $\mathrm{j}$ en el $\mathrm{T}_{2}, \mathrm{y}$ $100-\mathrm{P}_{\mathrm{i}+}$ es la suma de los tamaños de todas las categorías, excepto i en $\mathrm{T}_{2}$.

Al determinar las proporciones esperadas bajo un proceso aleatorio de cambio se puede calcular la diferencia entre ganancias esperadas y ganancias observadas (Versace, et al., 2008). Esta diferencia provee información sobre la tasa a la que cualquier clase ganará o perderá al azar. Apoyados en Pontius Jr. (2004) se asume que los valores cercanos a cero indican que la transición paisaje fue al azar, mientras que valores más lejos de cero indican una transición inter-categórica sistemática. La magnitud de la diferencia entre la ganancia observada (o pérdida) y ganancia esperada (o pérdida) cuantifica un patrón sistemático de cambio e indica el tamaño de su huella en el paisaje. La proporción de la diferencia en relación con el tamaño de la categoría indica la intensidad de las transiciones sistemáticas.

\section{Resultados}

\section{Ganancias y pérdidas}

La Figura 3 muestra que las ganancias, fueron más altas en las coberturas de vegetación natural (selva, manglar y P. Tular) entre 1993-2010, mientras que las ganancias de las demás categorías, fueron pequeñas $(<1 \%)$. Las categorías de vegetación natural, también sufrieron las mayores pérdidas $(\sim 91 \%$ en $1993-2000 \mathrm{y}$ $82 \%$ de 2000-2010 de las pérdidas totales). La cobertura urbana experimentó casi ninguna pérdida $(<0.1 \%)$ durante los dos períodos de estudio. 


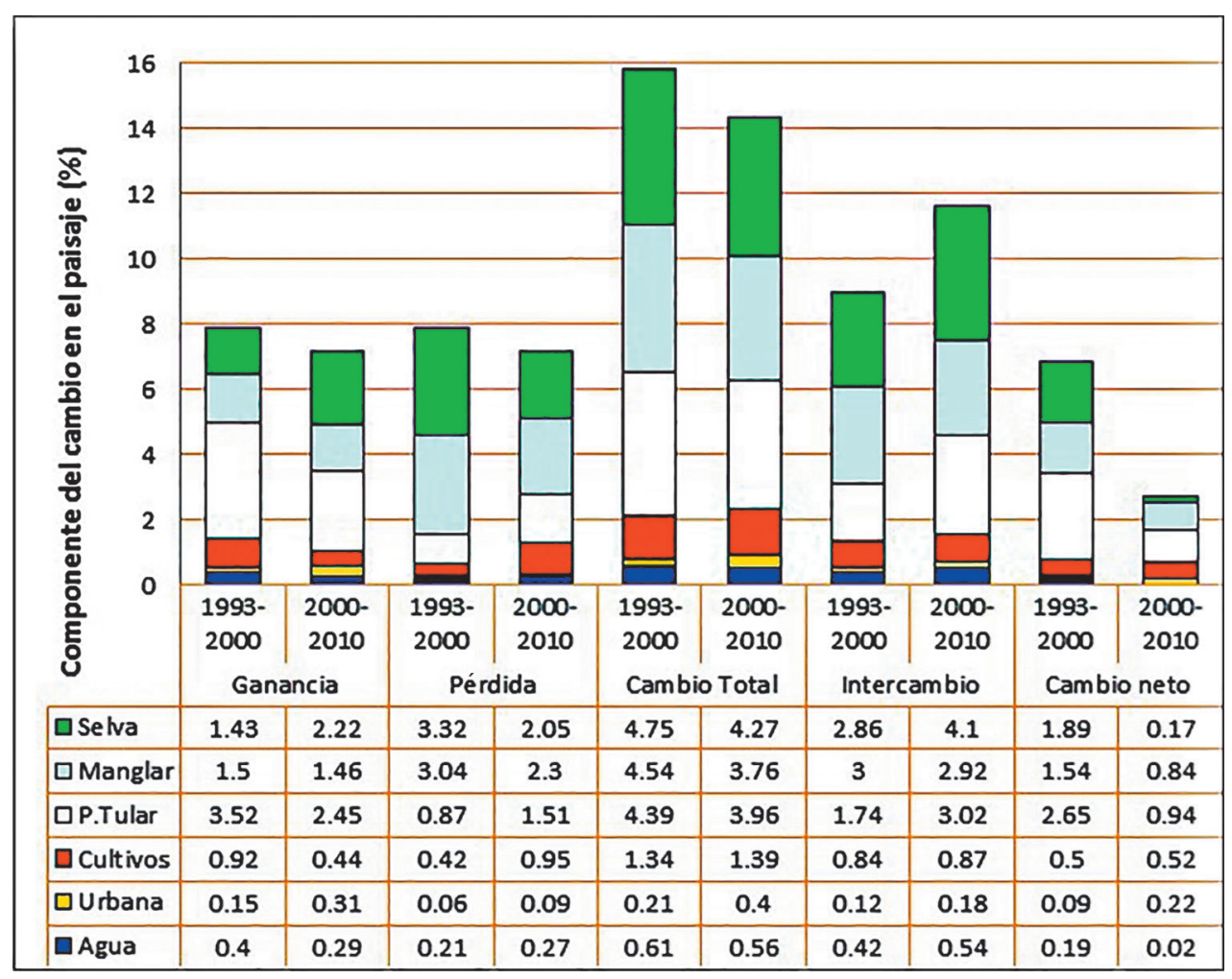

Figura 3. Resumen de los componentes del cambio en el paisaje (\%) entre 1993-2000 y $2000-2010$

Fuente: Elaboración propia, con datos de matrices de transición.

a) Cambio neto y el intercambio

Solo una pequeña parte del paisaje $(\sim 7,5 \%)$, experimentó cambio en los dos períodos de estudio; de este cambio, el intercambio formó la mayor proporción $(57 \%$ y $72 \%$ en el primer y segundo período, respectivamente); el resto fue cambio neto (Figura 2). En el contexto de la categoría, el intercambio y cambio neto constituyen cambios en Agua durante 1993-2000, pero en el período 2000-2010, las transiciones son casi totalmente intercambio. El intercambio y cambio neto comprenden los tipos de cambios en las demás categorías.

En el primer período, exceptuando al P. Tular, en donde el cambio neto fue mayor, los cambios atribuidos a intercambio en otras categorías, fueron mayores que los cambios netos. El mismo patrón, se repitió en el segundo período, aunque 
en este caso fue la categoría Zona urbana la que tuvo el cambio neto mayor que el Intercambio. El mayor cambio está asociado con las clases de vegetación naturales que, colectivamente, constituyen la clase más grande del paisaje $(\sim 80 \%$ en ambos períodos).

\section{b) Persistencia y vulnerabilidad} a transición

La Tabla 1 revela el predominio de la persistencia $(92 \%$ y el $93 \%)$ en el paisaje de 1993-2000 y de 20002010, respectivamente.

Tabla 1. Las relaciones ganancia-a la-persistencia (gp), pérdida-a la-persistencia (Lp) y cambio-neto -a la-persistencia $(\mathrm{Np})$, y vulnerabilidad de cada categoría a cambiar

\begin{tabular}{|l|c|c|c|c|c|c|c|c|}
\hline \multirow{2}{*}{ Categoría } & \multicolumn{2}{|c|}{ Persistencia (P) } & \multicolumn{2}{|c|}{$\mathbf{g}_{\mathrm{p}}$} & \multicolumn{2}{c|}{$\mathbf{L}_{\mathbf{p}}$} & \multicolumn{2}{c|}{$\mathbf{N}_{\mathbf{p}}$} \\
\cline { 2 - 9 } & $\mathbf{1 9 9 3 - 2 0 0 0}$ & $\mathbf{2 0 0 0 - 2 0 1 0}$ & $\mathbf{1 9 9 3 - 2 0 0 0}$ & $\mathbf{2 0 0 0 - 2 0 1 0}$ & $\mathbf{1 9 9 3 - 2 0 0 0}$ & $\mathbf{2 0 0 0 - 2 0 1 0}$ & $\mathbf{1 9 9 3 - 2 0 0 0}$ & $\mathbf{2 0 0 0 - 2 0 1 0}$ \\
\hline Agua & 45.39 & 45.53 & 0 & 0 & 0 & 0 & 0 & 0 \\
\hline Urbana & 0.26 & 0.33 & 0.58 & 0.94 & 0.23 & 0.27 & 0.35 & 0.67 \\
\hline Cultivos & 0.40 & 0.38 & 2.3 & 1.16 & 1.05 & 2.50 & 1.25 & -1.34 \\
\hline P. Tular & 4.81 & 6.79 & 0.73 & 0.36 & 0.18 & 0.22 & 0.55 & 0.14 \\
\hline Manglar & 4.78 & 3.98 & 0.31 & 0.37 & 0.64 & 0.58 & -0.33 & -0.21 \\
\hline Selva & 36.44 & 35.82 & 0.04 & 0.06 & 0.09 & 0.06 & -0.05 & 0 \\
\hline
\end{tabular}

Fuente: Elaboración propia, con base en datos de Figura 1.

La persistencia en la vegetación natural, fue mucho mayor que en otras clases, en ambos períodos de estudio. Las categorías Agua y Selva, presentaron los mayores $(>35 \%)$ y menores valores $(\sim 0)$ de los índices $\mathbf{P}$ y de $\mathbf{g}_{\mathrm{p}}$, respectivamente, durante período 1993-2010. La categoría cultivos, fue la única cobertura que registró valores de $\mathbf{g}_{\mathbf{p}}>0$, en los dos períodos de estudio. Asimismo, se observó un patrón similar para el índice $\mathbf{L}_{\mathbf{P}}$, en el que Cultivo fue la única categoría con $\mathbf{L}_{\mathbf{P}}>1$. Nuevamente, siguiendo a Braimoh (2006), las categorías con la relación $\mathbf{L}_{\mathbf{p}}>1$ indican una mayor tendencia a cambiar a otras clases que a persistir. En contraste, solo la categoría manglar presentó valores negativos de $\mathrm{N}_{\mathrm{p}}(-0,33$ y $-0,21)$ en ambos períodos de tiempo, respectivamente. Mientras que la relación $\mathbf{N}_{\mathbf{p}}$ de la categoría selva, fue negativa $(-0,05)$, en el período 1993-2000, y cero de 2000-2010. Las relaciones $\mathbf{N}_{\mathbf{p}}$ para el resto de las clases, fueron positivas en ambos periodos de estudio, exceptuando cultivo, el cual registró un valor negativo $(-1,34)$ en el período 2000-2010. 
Procesos de Transición InterCategóricas

\section{a) Matrices extendidas de transición}

\section{Las Tablas 2 y 3 son las matrices} de cambio o transición derivadas de la tabulación cruzada de las colecciones de mapas para los períodos 1993-2000 y 2000-2010, en donde las filas despliegan los valores de las categorías de mapa 1 y las columnas las del mapa 2 . Las matrices (Tabla 2), muestran cuatro números para cada combinación de categorías, en cada respectivo período de tiempo. El número de arriba escrito en negrita es el porcentaje de la combinación observada en el paisaje. Debajo de ese número, en cursiva, se indica el porcentaje del paisaje que se esperaría si el proceso de cambio fuera aleatorio. El tercer número, entre paréntesis (), es el número en negrita menos el número en cursiva, $\mathbf{P}_{\mathrm{ij}}-\mathbf{G}_{\mathrm{ij}}$. Una transición es sistemática si la transición observada se desvía de la transición que se esperaría (en cursiva). El cuarto número, entre corchetes [], es la diferencia relativa de la combinación entre el número observado y el número esperado. La tabla 3 presenta el análisis análogo, pero examinando el proceso aleatorio de pérdida.

Tabla 2. Matriz de cambio para 1993-2000, bajo procesos aleatorios de ganancias.

Con los valores (\%) de transición observados (tipo de letra negrita), pérdidas esperadas (itálicas), y ganancias esperadas (normal) entre categorías

\begin{tabular}{|c|c|c|c|c|c|c|c|c|c|c|c|c|c|c|c|c|c|}
\hline (A) & \multicolumn{8}{|c|}{2000} & (B) & \multicolumn{8}{|c|}{2010} \\
\hline 1993 & Agua & Z. Urbana & Cultivos & P. Tular & Manglar & Selva & $\begin{array}{c}1993 \\
\text { (Total) }\end{array}$ & Pérdidas & 2000 & Agua & Z. Urbana & Cultivos & P. Tular & Manglar & Selva & $\begin{array}{c}1993 \\
\text { (Total) }\end{array}$ & Pérdidas \\
\hline Agua & $\begin{array}{l}\mathbf{4 5 . 3 9} \\
45.39 \\
(0.00) \\
{[0.00]}\end{array}$ & $\begin{array}{c}\mathbf{0 . 0 0} \\
0.07 \\
(-0.07) \\
{[-1.00]}\end{array}$ & $\begin{array}{c}\mathbf{0 . 0 0} \\
0.43 \\
(-0.43) \\
{[-1.00]}\end{array}$ & $\begin{array}{c}0.07 \\
1.70 \\
(-1.68) \\
{[-0.961]}\end{array}$ & \begin{tabular}{|c|c}
$\mathbf{0 . 1 2}$ \\
0.74 \\
$(-0.61)$ \\
{$[-0.84]$}
\end{tabular} & $\begin{array}{c}\mathbf{0 . 0 2} \\
1.08 \\
(-1.03) \\
{[-0.98]}\end{array}$ & $\begin{array}{l}\mathbf{4 5 . 6 0} \\
49.41 \\
(-3.81) \\
{[-0.08]}\end{array}$ & $\begin{array}{c}\mathbf{0 . 2 1} \\
4.02 \\
(-3.81) \\
{[-0.95]}\end{array}$ & Agua & $\begin{array}{l}\mathbf{4 5 . 5 3} \\
45.53 \\
(0.00) \\
{[0.00]}\end{array}$ & $\begin{array}{c}0.00 \\
0.14 \\
(-0.14) \\
{[-1.00]}\end{array}$ & $\begin{array}{c}0.01 \\
0.20 \\
(-0.19) \\
{[-0.95]}\end{array}$ & $\begin{array}{c}0.15 \\
1.22 \\
(-1.09) \\
{[-0.88]}\end{array}$ & $\begin{array}{c}0.08 \\
0.71 \\
(-0.63) \\
{[-0.89]}\end{array}$ & $\begin{array}{c}0.03 \\
1.63 \\
(-1.61) \\
{[-0.98]}\end{array}$ & $\begin{array}{c}45.80 \\
49.43 \\
(-3.63) \\
{[-0.07]}\end{array}$ & $\begin{array}{c}0.27 \\
3.90 \\
(-3.63) \\
{[-0.93]}\end{array}$ \\
\hline Z. Urbana & $\begin{array}{c}\mathbf{0 . 0 0} \\
0.002 \\
(-.002) \\
{[-1.00]}\end{array}$ & $\begin{array}{c}\mathbf{0 . 2 6} \\
0.26 \\
(0.00) \\
{[0.00]}\end{array}$ & $\begin{array}{c}\mathbf{0 . 0 2} \\
0.003 \\
(0.02) \\
{[5.67]}\end{array}$ & $\begin{array}{c}0.00 \\
0.01 \\
(-0.01) \\
{[-1.00]}\end{array}$ & $\begin{array}{c}\mathbf{0 . 0 2} \\
0.01 \\
(0.01) \\
{[1.00]}\end{array}$ & $\begin{array}{c}\mathbf{0 . 0 2} \\
0.01 \\
(0.01) \\
{[1.80]}\end{array}$ & $\begin{array}{c}\mathbf{0 . 3 2} \\
0.29 \\
(0.03) \\
{[0.10]}\end{array}$ & $\begin{array}{c}\mathbf{0 . 0 6} \\
0.03 \\
(0.03) \\
{[1.00]}\end{array}$ & Z. Urbana & $\begin{array}{c}\mathbf{0 . 0 1} \\
0.002 \\
(0.008) \\
{[4.00]}\end{array}$ & $\begin{array}{c}0.33 \\
0.33 \\
(0.00) \\
{[0.00]}\end{array}$ & $\begin{array}{c}0.01 \\
0.002 \\
(0.01) \\
{[4.00]}\end{array}$ & $\begin{array}{c}0.00 \\
0.01 \\
(-0.01) \\
{[-1.00]}\end{array}$ & $\begin{array}{c}0.02 \\
0.01 \\
(0.01) \\
{[1.00]}\end{array}$ & $\begin{array}{c}0.05 \\
0.02 \\
(0.03) \\
{[1.50]}\end{array}$ & $\begin{array}{c}0.42 \\
0.37 \\
(0.05) \\
{[0.14]}\end{array}$ & $\begin{array}{c}0.09 \\
0.04 \\
(0.05) \\
{[1.25]}\end{array}$ \\
\hline P. Tular & $\begin{array}{c}\mathbf{0 . 1 2} \\
0.04 \\
(0.08) \\
{[\mathbf{2 . 0 0}]} \\
\end{array}$ & $\begin{array}{c}\mathbf{0 . 0 0} \\
0.01 \\
(-0.01) \\
{[-1.00]}\end{array}$ & $\begin{array}{c}\mathbf{0 . 0 1} \\
0.05 \\
(-0.04) \\
{[-0.80]}\end{array}$ & $\begin{array}{c}\mathbf{4 . 8 1} \\
4.81 \\
(0.00) \\
{[0.00]}\end{array}$ & $\begin{array}{c}\mathbf{0 . 4 9} \\
0.09 \\
(0.40) \\
{[4.44]}\end{array}$ & $\begin{array}{c}\mathbf{0 . 2 5} \\
0.13 \\
(0.12) \\
{[0.92]} \\
\end{array}$ & $\begin{array}{c}\mathbf{5 . 6 8} \\
5.13 \\
(0.55) \\
{[0.11]} \\
\end{array}$ & $\begin{array}{c}\mathbf{0 . 8 7} \\
0.32 \\
(0.55) \\
{[1.72]} \\
\end{array}$ & P. Tular & $\begin{array}{c}0.09 \\
0.04 \\
(0.05) \\
{[1.25]}\end{array}$ & $\begin{array}{c}0.00 \\
0.03 \\
(-0.03) \\
{[-1.00]}\end{array}$ & $\begin{array}{c}0.01 \\
0.04 \\
(-0.03) \\
{[-0.75]}\end{array}$ & $\begin{array}{c}6.79 \\
6.79 \\
(0.00) \\
{[0.00]} \\
\end{array}$ & $\begin{array}{c}0.89 \\
0.13 \\
(0.76) \\
{[5.85]}\end{array}$ & $\begin{array}{c}0.52 \\
0.30 \\
(0.22) \\
{[0.73]}\end{array}$ & $\begin{array}{c}8.30 \\
7.33 \\
(0.97) \\
{[0.13]} \\
\end{array}$ & $\begin{array}{c}1.51 \\
0.54 \\
(0.97) \\
{[1.80]}\end{array}$ \\
\hline Manglar & $\begin{array}{c}\mathbf{0 . 2 2} \\
0.06 \\
(0.16) \\
{[2.67]}\end{array}$ & $\begin{array}{c}\mathbf{0 . 0 1} \\
0.01 \\
(0.00) \\
{[0.00]}\end{array}$ & $\begin{array}{c}\mathbf{0 . 0 1} \\
0 . \mathrm{Q}^{2} \\
(-0.06) \\
{[-0.86]}\end{array}$ & $\begin{array}{c}\mathbf{1 . 9 9} \\
0.29 \\
(1.69) \\
{[5.63]}\end{array}$ & $\begin{array}{c}4.78 \\
4.78 \\
(0.00) \\
{[0.00]}\end{array}$ & $\begin{array}{c}\mathbf{0 . 8 1} \\
0.19 \\
(0.63) \\
{[3.50]}\end{array}$ & $\begin{array}{c}\mathbf{7 . 8 2} \\
5.40 \\
(2.42) \\
{[0.45]}\end{array}$ & $\begin{array}{c}\mathbf{3 . 0 4} \\
0.62 \\
(2.42) \\
{[3.90]}\end{array}$ & Manglar & $\begin{array}{c}0.17 \\
0.03 \\
(0.14) \\
{[4.67]}\end{array}$ & $\begin{array}{c}0.04 \\
0.02 \\
(0.02) \\
{[1.001]}\end{array}$ & $\begin{array}{c}0.02 \\
0.03 \\
(-0.01) \\
{[-0.33]}\end{array}$ & $\begin{array}{c}1.23 \\
0.17 \\
(1.06) \\
{[6.24]}\end{array}$ & $\begin{array}{c}3.98 \\
3.98 \\
(0.00) \\
{[0.00]}\end{array}$ & $\begin{array}{c}0.84 \\
0.22 \\
(0.61) \\
{[2.65]}\end{array}$ & $\begin{array}{l}6.28 \\
4.45 \\
(1.83) \\
{[0.41]} \\
\end{array}$ & $\begin{array}{c}2.30 \\
0.47 \\
(1.83) \\
{[3.89]}\end{array}$ \\
\hline $\begin{array}{c}2000 \\
\text { (Total) }\end{array}$ & $\begin{array}{l}\mathbf{4 5 . 7 9} \\
45.79 \\
(0.00) \\
{[0.00]}\end{array}$ & $\begin{array}{c}\mathbf{0 . 4 1} \\
0.41 \\
(0.00) \\
{[0.00]} \\
\end{array}$ & $\begin{array}{c}\mathbf{1 . 3 2} \\
1.32 \\
(0.00) \\
{[0.00]} \\
\end{array}$ & $\begin{array}{c}\mathbf{8 . 3 3} \\
8.33 \\
(0.00) \\
{[0.00]} \\
\end{array}$ & $\begin{array}{c}\mathbf{6 . 2 8} \\
6.28 \\
(0.00) \\
{[0.00]} \\
\end{array}$ & $\begin{array}{l}37.87 \\
37.87 \\
(0.00) \\
{[0.00]}\end{array}$ & 100 & & $\begin{array}{c}2000 \\
\text { (Total) }\end{array}$ & $\begin{array}{l}45.82 \\
45.82 \\
(0.00) \\
{[0.001]}\end{array}$ & $\begin{array}{c}0.64 \\
0.64 \\
(0.00) \\
{[0.00]} \\
\end{array}$ & $\begin{array}{c}0.82 \\
0.82 \\
(0.00) \\
{[0.00]}\end{array}$ & $\begin{array}{c}9.24 \\
9.24 \\
(0.00) \\
{[0.00]} \\
\end{array}$ & $\begin{array}{c}5.44 \\
5.44 \\
(0.00) \\
{[0.00]}\end{array}$ & $\begin{array}{l}38.04 \\
38.04 \\
(0.00) \\
{[0.00]}\end{array}$ & 100 & \\
\hline Ganancias & $\begin{array}{c}\mathbf{0 . 4 0} \\
0.40 \\
(0.00) \\
{[0.00]}\end{array}$ & $\begin{array}{c}\mathbf{0 . 1 5} \\
0.00 \\
(0.00) \\
{[0.00]}\end{array}$ & $\begin{array}{c}\mathbf{0 . 9 2} \\
0.92 \\
(0.00) \\
[0.00)]\end{array}$ & $\begin{array}{c}3.52 \\
3.52 \\
(0.00) \\
{[0.00]}\end{array}$ & $\begin{array}{c}\mathbf{1 . 5 0} \\
1.50 \\
(0.00) \\
{[0.00]}\end{array}$ & $\begin{array}{c}\mathbf{1 . 4 3} \\
1.43 \\
(0.00) \\
{[0.00]}\end{array}$ & & $\Sigma=7.92$ & Ganancias & $\begin{array}{c}0.29 \\
0.29 \\
(0.00) \\
{[0.00]}\end{array}$ & $\begin{array}{c}0.31 \\
0.31 \\
(0.00) \\
{[0.00]}\end{array}$ & $\begin{array}{c}0.44 \\
0.44 \\
(0.00) \\
{[0.00]}\end{array}$ & $\begin{array}{l}2.45 \\
2.45 \\
(0.00) \\
{[0.00)}\end{array}$ & $\begin{array}{c}1.46 \\
1.46 \\
(0.00) \\
{[0.00]}\end{array}$ & $\begin{array}{c}2.22 \\
2.22 \\
(0.00) \\
{[0.00]}\end{array}$ & & $\Sigma=7.17$ \\
\hline
\end{tabular}

Fuente: Elaboración propia. 
Tabla 3. Matriz de cambio para 1993-2000 y 2000-2010, bajo procesos aleatorios de pérdidas.

Con los valores (\%) de transición observados (tipo de letra negrita), pérdidas esperadas (cursivas), y ganancias esperadas (normal) entre categorías

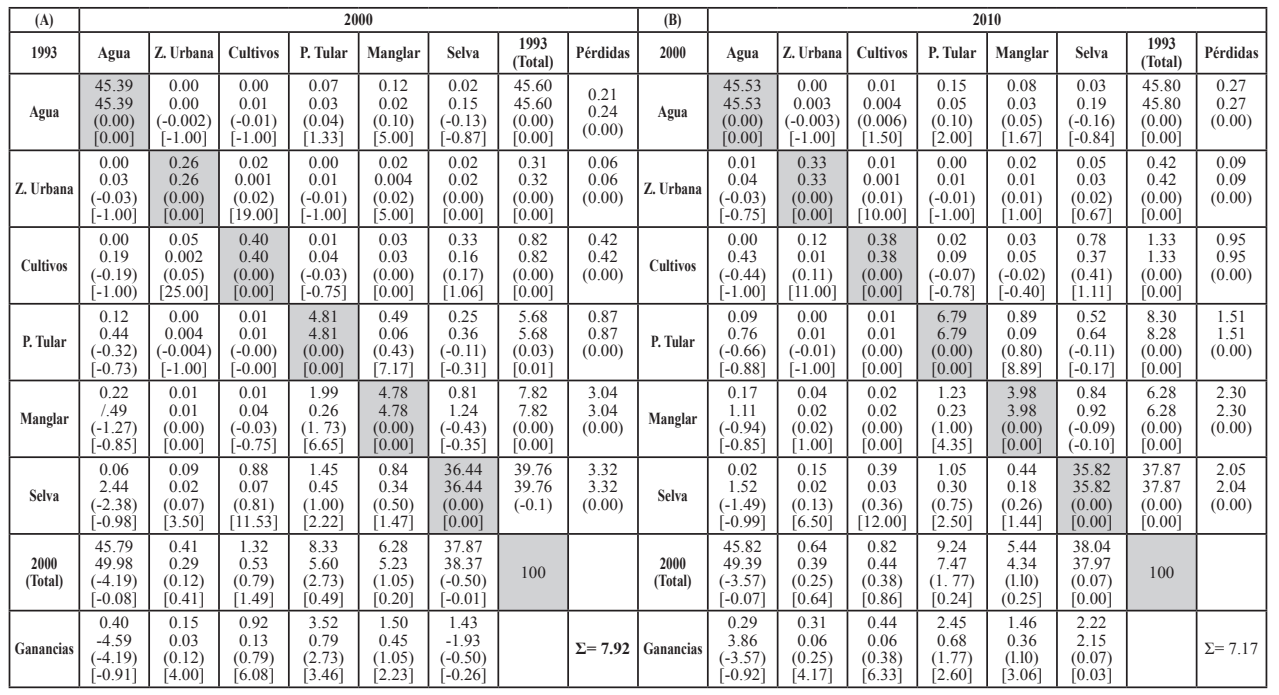

Fuente: Elaboración propia.

b) Las transiciones sistemáticas más relevantes en el RCM

La Tabla 4 presenta las transiciones sistemáticas más relevantes en la RCM, considerando el porcentaje de cambio en términos de ganancias y pérdidas, interpretados de las matrices de transiciones (Tablas 2 y 3$)$.

La primera fila indica un patrón sistemático en el que Agua reemplaza Manglar a $\sim 3$ y $\sim 5$ veces la tasa que se esperaría, si Agua ganara aleatoriamente durante 1993 - 2000 y 2000 - 2010, respectiva- mente. Las categorías no-Agua tendían a evitar reemplazar Agua, cuando ganaran al azar. Las diferencias entre las ganancias observadas y esperadas son positivos en la segunda fila, lo que corrobora patrones sistemáticos en los cuales Urbana, Selva y categorías no-Cultivos se inclinaban a reemplazar a Cultivos, cuando ganaron alza. Las intensidades (49 de 1993 - $2000 \mathrm{y}$ 30 de 2000 - 2010) de la transición sistemáticas: Cultivos $\rightarrow$ Urbana, fueron las más altas registradas en el paisaje, lo que indica que dicha transición, era la más fuerte en el paisaje. 
Tabla 4. Las transiciones sistemáticas más relevantes en el RCM bajo procesos aleatorios de cambios (\%) de ganancias y pérdidas

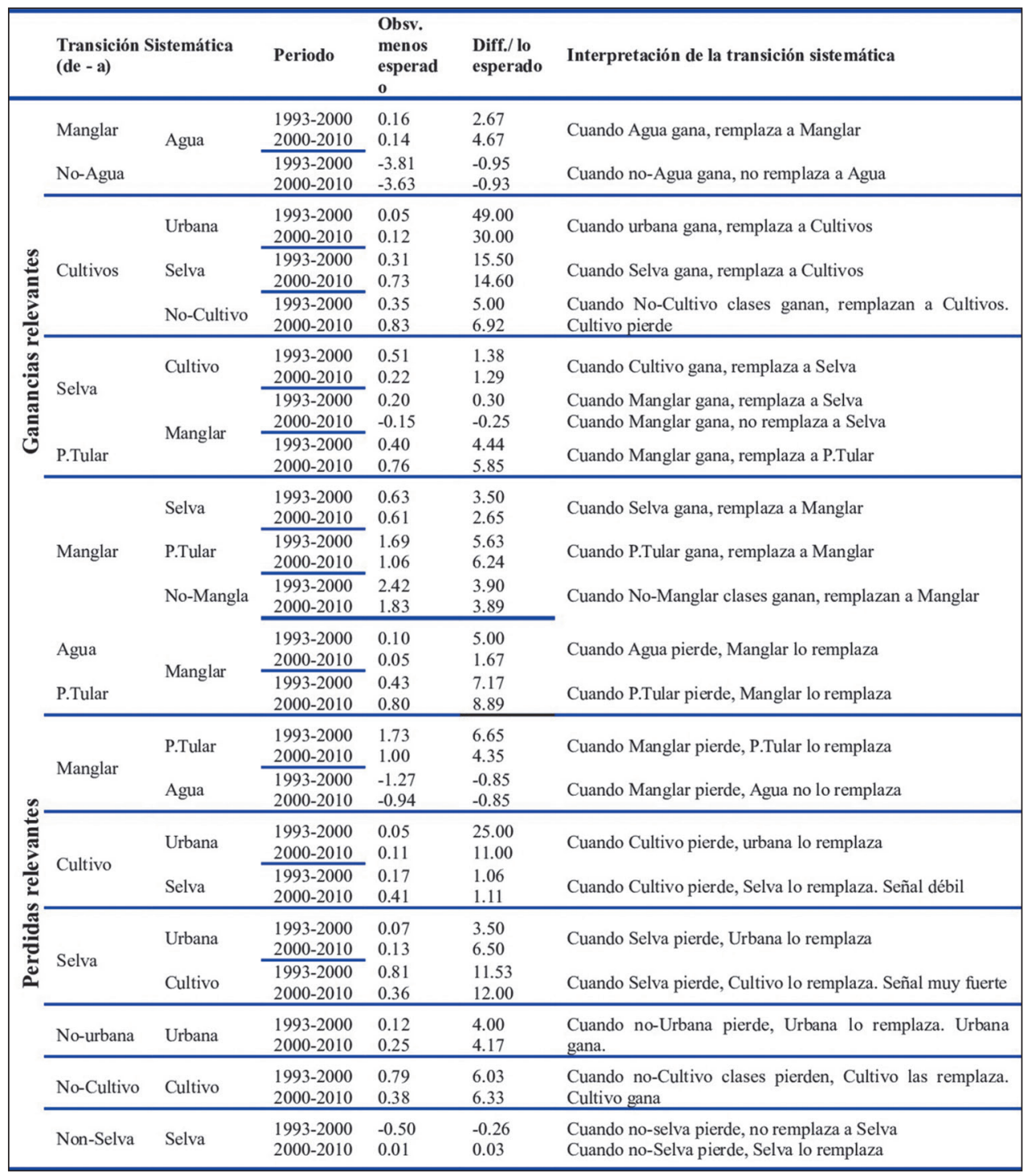

Fuente: Elaboración propia, con base en datos de las Tablas 2 y 3. 
En la tercera fila, las diferencias entre las ganancias observadas y esperadas son positivas para las transiciones: Selva $\rightarrow$ cultivos, Selva $\rightarrow$ manglares (solo entre1993-2000). Esto muestra que cuando Cultivo ganó, tendían a reemplazar, sistemáticamente, Selva, y fue poco dispuesto a sustituir manglar entre 2000 2010 bajo procesos aleatorios, a pesar de que las señales eran débiles $(<1,40)$. En las dos últimas filas, las diferencias entre las ganancias observadas y esperadas son positivas, lo cual implica que cuando Selva, P. Tular y categorías No-Manglar ganaron al azar, se inclinaba a sustituir a Manglar, pero cuando Manglar ganó, tendía a reemplazar a $\mathrm{P}$. Tular.

Con respecto a las relaciones bajo procesos aleatorios de pérdidas, la primera y segunda filas indican que cuando las categorías perdieron, tendían a ser reemplazados por Manglar y P. Tular, pero no por Agua. La tercera fila afirma que cuando Cultivo perdió, se inclinaba a ser sustituido, sistemáticamente, por urbana y Selva (en un grado mucho menor); pero cuando Selva perdió (la cuarta fila), se inclinaba a ser reemplazada, sistemáticamente, por cultivo, a 12 veces, y a urbana a 3.5 y 6.5 veces las tasas que se esperaría, si el proceso fuera bajo procesos aleatorios de pérdida. Las tres últimas filas corroboran que cuando otras categorías perdieron, tendían a ser sustituidos por Urbana, Cultivo y no por Selva (solo en 1993-2000).

\section{Discusión}

\section{Evaluación de la cantidad de cambio}

El análisis muestra que la persistencia, principalmente en Agua y en la vegetación naturales (Selva, Manglar y Popal-Tular), es, aproximadamente, $90 \%$ de la RCM. Se puede atribuir el alto grado de persistencia a la existencia en la región de sitios protegidos: reserva de la biosfera de Sian Káan, Manatí, y bosques de manglar y humedales, los cuales cuentan con la protección del gobierno. Además, como se indicó en la introducción, RCM es una creación "reciente" del gobierno del Estado (en 1993) para impulsar el desarrollo económico en la zona sur de Quintana Roo, basado en el turismo.

Al dominar el paisaje, la vegetación natural es la matriz del 
mismo, en la que ocurren todos los intercambios entre las clases; los más prominentes, en términos de porcentaje de paisaje, son entre Selva y P. Tular, Manglar y P. Tular. Resulta tentador suponer las transiciones entre estas categorías, como las más sistemáticas (Tabla 2 y 3 ), con base en sus altas proporciones $(>1 \%)$. Sin embargo, tal interpretación es engañosa, ya que no toma en cuenta que la Selva (37\%), Manglar (1\%) y Popal-Tular (1\%), son las categorías más grandes del paisaje (tabla 2 y 3). Magnitud que por sí sola no es suficiente evidencia para determinar si una transición es aleatorio o sistemático (Manandhar, et al., 2010), ya que, incluso, un proceso aleatorio de cambio terrestre, causaría grandes transiciones dentro de estas clases (Pontius Jr., et al., 2004).

\section{Análisis del intercambio y vulnerabilidad a la transición}

La Tabla 1 revela qué Cultivo es la única clase con valores $>1$ de $\mathbf{g}_{\mathrm{p}}$ y $\mathbf{L}_{\mathbf{p}}$; indicando que, a pesar de su pequeña proporción en el paisaje $(0,4 \%$ en 2000 y $0,5 \%$ en 2010), presenta las mayores tendencias de ganar y perder, sobre la de persistir. Dichas tendencias son dominantes durante los dos periodos del estudio. Alto valor de $\mathbf{g}_{\mathbf{p}}$ durante 1993-2000 sugiere una expansión de las actividades agrícolas (especialmente en el chile, maíz, caña y aumento de la ganadería extensiva) en respuesta a los incentivos del gobierno (Turner II, 2010). Dichas tendencias son corroboradas por la mayor inclinación de Cultivo a ganar área, que a perderla, frente a otros tipos de cobertura durante 19932000. Sin embargo, esta tendencia revirtió en el segundo período (tabla 1), debido al barbecho y abandono de tierras agrícolas. El intercambio $(\sim 0,86 \%)$ en Cultivo es mayor que el cambio neto durante 1993-2010; lo que implica el predominio de la práctica de la agricultura migratoria mediante el sistema de roza tumba y quema (Velásquez, 2007; Turner II, 2010). La intensificación agrícola explica la persistencia en Cultivos.

Agua y Selva, las dos categorías más grandes ( $\sim 84 \%$ del paisaje), muestran índices de vulnerabilidad a cambio de casi cero (Figura 3), lo que implica mayor tendencia hacia la estabilidad (Braimoh, 2006). Cambio en estas clases es casi puro intercambio, confirmado por casi cero valores de $\mathbf{N}_{\mathbf{p}}$. En contraste, los 
valores negativos $\mathbf{N}_{\mathbf{p}}$ de Manglar, indican una alta tendencia a perder, sobre la de ganar de otras clases (Braimoh, 2006). Se puede atribuir a las altas pérdidas o deforestación en manglares, especialmente, en el Corredor turístico Costa Maya (que va desde Majahual a Xcalak), a la construcción de infraestructura turística (carreteras, hoteles, muelles), lo cual ocasiona la destrucción de manglares y otros ecosistemas marinos; también, los manglares son expuestos a agentes de perturbaciones naturales (tormentas y huracanes) que son comunes en la temporada de lluvias, de junio a noviembre (DiazGallegos \& Acosta-Velázquez, 2009; Hirales-Cota, et al., 2010).

\section{Transiciones entre-categorías}

Cambio total ( $\sim 8 \%$ del paisaje); es casi doble la variación global neta entre 1993 y 2000 , pero aumenta a, aproximadamente, cinco veces el cambio global neto durante el período 2000-2010 (Figura 3). Por tanto, el intercambio y cambio neto son importantes para entender el cambio total en cualquier paisaje. Pontius Jr. (2004) advierte que representar solo el cambio neto, podría llevar a una subestimación dramática de cambio total; el autor afirma que el análisis de persistencia, ganancias y pérdidas es instructivo; sin embargo, no informan si las transiciones entre las categorías son sistemáticas o aleatorias. En este sentido, se examinó los cambios en el paisaje, utilizando métodos estadísticos novedosos (apartado 3) que toman en cuenta la persistencia, ya que la persistencia domina en el RCM.

Este método permite distinguir entre cambios sistemáticos y aleatorios del paisaje; sin embargo, no se puede considerar cualquier transición sistemática, como la señal dominante en el paisaje. Según Braimoh (2006) and Alo \& Pontius (2008), solo se la pueda inferir, por ejemplo, cuando una categoría $\mathrm{X}$ remplaza sistemáticamente la categoría $\mathrm{Y}$, y la categoría $\mathrm{Y}$ pierde área sistemáticamente sobre la categoría $\mathrm{X}$. Con base en esta condición, las señales dominantes de los cambios en la RCM durante 1993-2010, mostradas en los siguientes dos mapas (Figuras 4 y 5) son: Cultivo $\rightarrow$ Urbana; intercambios entre Cultivo y Selva; y Manglar $\rightarrow$ P. Tular. 


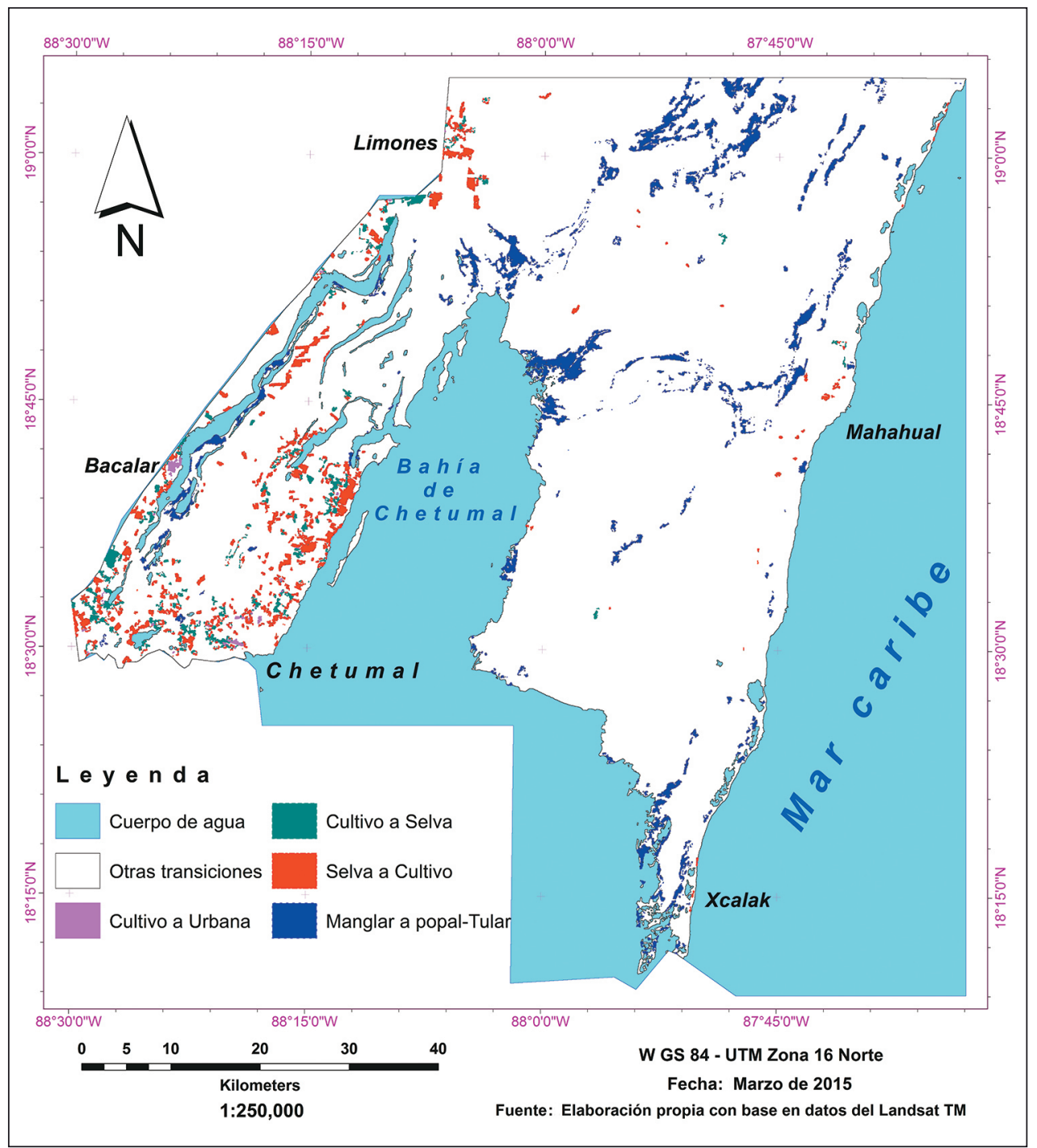

Figura 4. Mapas de las transiciones sistemáticas en la RCM, 1993-2000

Fuente: Elaboración propia. 


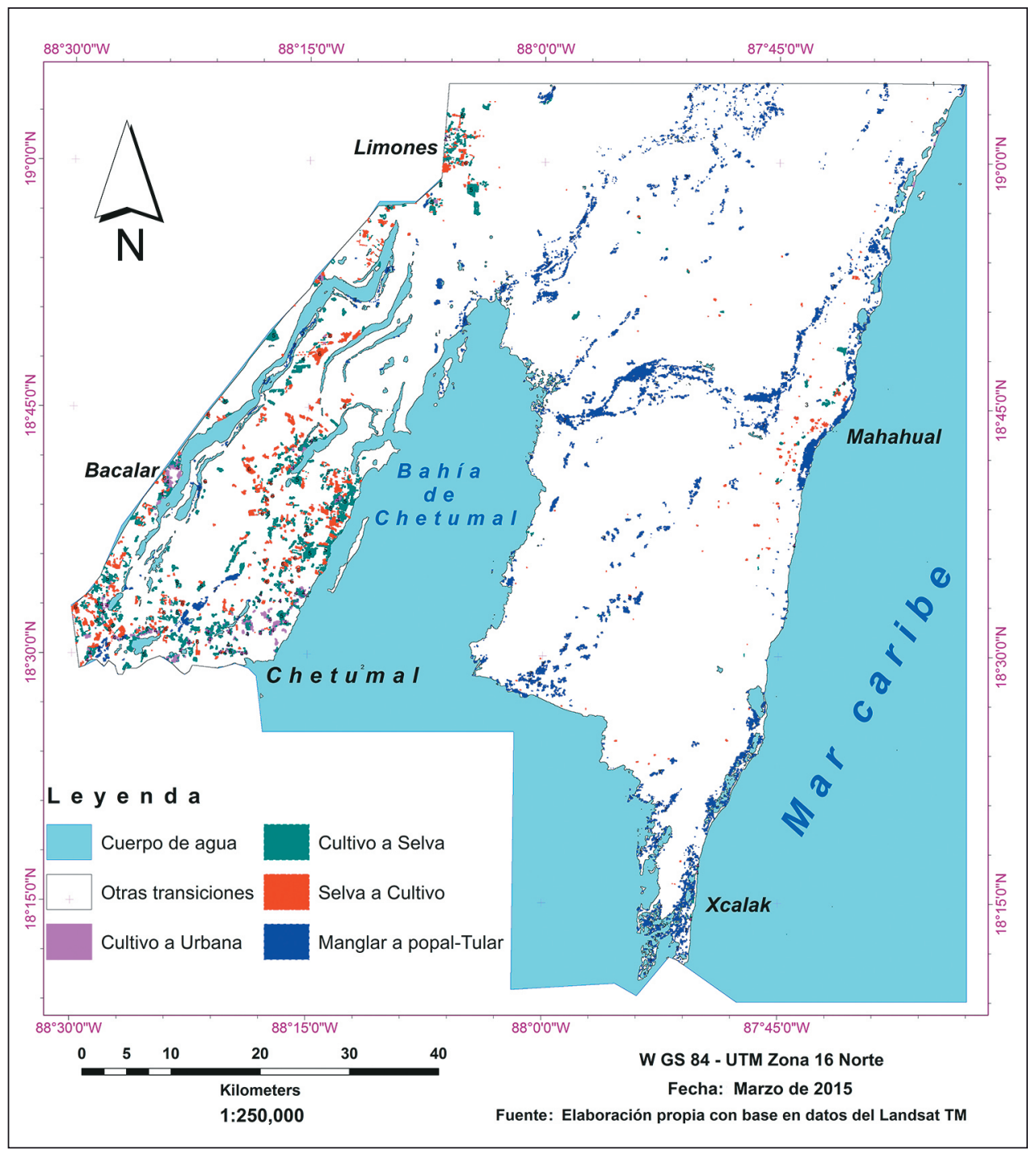

Figura 5. Mapas de las transiciones sistemáticas en la RCM, 2000-2010

Fuente: Elaboración propia. 
Las señales dominantes (discutidas a continuación), nos permiten identificar los procesos potenciales de cambios en la RCM, los cuales son: urbanización, deforestación, expansión agrícola, la reforestación y el abandono de tierras.

\section{a) Transición: Cultivo $\rightarrow$ Urbana o el proceso de urbanización}

La transición sistemática más fuerte en RCM es la de Cultivo $\rightarrow$ Urbana, con valores 49 para 19932000 y 30 para 2000-2010 (Tabla 4); ello implica que urbanización es el proceso más fuerte del paisaje. Se puede confirmar el cambio irreversible de urbanización por la fuerte inclinación de la Zona Urbana a reemplazar Cultivo, cuando gana, evitando, al mismo tiempo, ser sistemáticamente sustituidos por clases No-urbanas; fortalecida por una inclinación similar de cultivo de ser sustituido por Zona Urbana cuando Cultivo pierde bajo proceso aleatorio de pérdida. Alta tendencia a la permanencia (Tabla 1) en Zona Urbana es también corroborada por los valores positivos de $\mathbf{N}_{\mathbf{p}}$, lo que indica una mayor tendencia a ganar área que a perderla sobre otras clases (Braimoh, 2006).
Estos resultados no son sorprendentes, ya que las zonas urbanas (Figura 2) están rodeadas de campos de cultivos, lo que significa que cualquier expansión espacial en la zona ocurre a expensas de Campo agrícola; como se observó, alrededor de principales asentamientos urbanos como Chetumal, la capital de la Quintana Roo, Majahual-Xcalak y Bacalar. Dicha sustitución de las tierras agrícolas es muy bien conocida en todo el mundo, en general, y en la península de Yucatán, en particular (Velásquez, 2007). Las altas magnitudes de cambios sistemáticas en ambos períodos de estudio se deben a factores socio-económicos y políticos que favorecen desarrollo de turismo.

\section{b) Intercambio entre Cultivo y} Selva

Los intercambios entre Cultivo y Selva indican una fuerte inclinación de la Selva a reemplazar Cultivos, más de 10 veces la tasa a la que Cultivo sustituye a Selva (Tabla 4). Esta tendencia es corroborada por la fuerte inclinación de Cultivo de perder sobre otras categorías bajo procesos aleatorios de pérdida, cuando otras categorías 
ganan. Se deben grandes pérdidas en Cultivo a Selva, al abandono de tierras, lo que revela fuertes declives en la agricultura. Se puede observar dicho proceso en los mapas (Figuras 4 y 5), concentrado entre las riberas de la laguna de Bacalar y la bahía de Chetumal; y al norte de la bahía de Chetumal. Se puede vincular dichas pérdidas a factores económicos, como la caída de los precios de productos agrícolas, la pérdida de incentivos gubernamentales (Velásquez, 2007; Turner II, 2010) y a una fuerte promoción del turismo.

La reforestación o la expansión selvática en tierras agrícolas abandonadas indica una disminución de la presión humana, y es consistente con la teoría de transición forestalun marco conceptual, según Farley (2010) para entender aquellos escenarios en los cuales los países pasan desde un período de pérdida de cobertura forestal hacia un período de incremento de cobertura forestal. Para más detalles, véase los trabajos de Farley, 2010 y Turner, 2010. En la RCM, las sendas de transición forestal más importantes están asociadas, en parte, con las políticas gubernamentales para modernizar la economía de México, específicamente, la eco- nomía agraria. Tales medidas restan importancia a la agricultura "marginal" del sistema ejidal, y tratan de aumentar las alternativas no agrícolas (como arqueo-ecoturismo), a los usuarios de las tierras afectadas (Turner II, 2010).

La senda al abandono de tierra agrícola es revisada en el trabajo de García-Rubio, et al. (2005), autores que la atribuyen a los siguientes factores: alta cantidad de personas que tienen trabajo remunerado que tiende a aumentar la falta de mano de obra para mantener grandes extensiones de áreas cultivadas; suelo no apto para agricultura y ganadería de alto rendimiento, y escasez de infraestructura para la producción intensiva. Otro factor es la creación de Áreas Naturales Protegidas (como las Reservas de la Biosfera de Sian Ka'an y de Banco Chinchorro; la Zona Sujeta a Conservación Ecológica "Santuario del Manatí, Bahía de Chetumal"), en donde se promueve la preservación de los bosques, incluidas las normas que restringen la tala de bosques entre los ejidos que residen dentro de la reserva. La transición: Cultivo $\rightarrow$ Selva o la deforestación de la Selva como validada por componentes más altos de intercambio en comparación 
con los cambios netos en Cultivo (Figura 3), es una indicación de la prevalencia de la agricultura migratoria en la RCM.

\section{c) Transición Manglar $\rightarrow P$. Tular}

P. Tular se caracterizó por una fuerte inclinación a reemplazar al Manglar cuando el P. Tular gana al azar (Tabla 4). Esto se corrobora por la fuerte tendencia del Manglar a perder frente al P. Tular y a otras categorías no-Manglares, en procesos aleatorios de pérdida. Las pérdidas continuas en Manglar, representadas como un proxy de ganancia en P. Tular, pueden atribuirse a la traza de líneas de delimitación de propiedades privadas dentro de la zona de manglar, a la tala para la construcción de hoteles, a la construcción de caminos y al impacto de los huracanes (Díaz-Gallegos \& Acosta-Velázquez, 2009; Hirales-Cota, et al., 2010).

\section{Conclusiones}

Este estudio, analizó los patrones de cambios del paisaje en la RCM, Quintana Roo, en dos períodos de tiempo (1993 a 2000 y 2000 a 2010). Para ello, se utilizó mapas raster multitemporales, un SIG y un análisis más detallado de la ma- triz de transición, para obtener una mejor comprensión de las transiciones entre categorías y procesos clave detrás de estas transiciones.

El estudio encontró que solo una pequeña proporción de la RCM ( $\sim 8 \%$ entre $1993-2000$ y el $\sim 7 \%$ entre 2000-2010), experimentó transiciones entre-categorías, dominado por Cambio neto $(\sim 81 \%)$ e Intercambio (19\%). El Intercambio es mayor que el Cambio Neto en las categorías con pérdidas netas. La inclusión de intercambio en la dinámica del cambio es importante para evitar interpretar la ausencia del cambio neto como ausencia de cambio, ya que el cambio neto no logra captar el componente de intercambio del cambio. Cultivo es la categoría más dinámica de la RCM, cuya tendencia a perder área sobre otras categorías en lugar de ganarla ha aumentado durante el período de estudio. La pérdida del ecosistema agrícola tiene implicaciones ambientales y económicas críticas para la región, y debería preocupar a las autoridades y las partes interesadas. Estadísticas de la vulnerabilidad a cambiar $\left(\mathrm{L}_{\mathrm{p}}>\mathrm{N}_{\mathrm{p}}\right.$ y $\mathrm{N}_{\mathrm{p}}<0$ ) para Manglar son preocupantes. A pesar de contar con la protección internacional y gubernamental, Manglar muestra una in- 
clinación fuerte y continua hacia la pérdida de superficie entre los años 1993-2010, lo que sugiere que las leyes y políticas ambientales existentes no han sido eficaces para evitar su destrucción. Las señales dominantes de transición en el RCM son: Cultivo a Zona Urbana; intercambios entre Cultivo y Selva; y Manglar a Popal-Tular. Estas transiciones, probablemente, indican una falta de crecimiento económico equilibrado en la RCM que es necesario abordar para evitar la degradación del medio ambiente. Estas señales se caracterizan por la disminución del sector agrícola, en comparación con el sector turismo, el cual está gozando un crecimiento rápido en la región, y es visto en expansión urbana. Ya que estos procesos asociados con señales dominantes son inducidos por las políticas, su regulación o reversión también tiene que ser activado con las políticas gubernamentales para aumentar la posibilidad de uso sostenible del suelo. El estudio ha revelado nuevas perspectivas sobre la naturaleza y procesos (tanto aleatorios como sistemáticos) del cambio en la RCM; que incluyen los cambios derivados de intercambio, y las tendencias de las coberturas terrestres para cambiar a otras categorías. No se habría observado esta información si el análisis se hubiera basado en la matriz de transición tradicional. Además, se habría centrado en los intercambios entre Selva y Manglar, con base en sus huellas ambientales dominantes en el paisaje; y habría perdido las transiciones sistemáticas en el paisaje. Imágenes raster de alta resolución deben ser utilizadas en futuros estudios para determinar las fuerzas motrices de los procesos de transición dominantes.

\section{Agradecimientos}

El primer autor agradece al Programa de Becas de Excelencia del Gobierno de México para Extranjeros, por su apoyo para la realización de su estudio de doctorado, del cual este trabajo forma parte.

\section{Referencias}

Aabeyir, R., Oduro, W. \& Quaye-Ballard, J. A. (2012). Analysis of the Processes behind Woodland Transition in Commercial Charcoal Producing Areas: A Case Study of Kintampo North District of Ghana. Research Journal of Environmental and Earth Sciences, 4(10), 866-877. 
Braimoh, A. (2006). Random and systematic land covers transitions in Ghana. Agriculture, Ecosystems and Environment, 113, 254-263.

Campos-Cámara, B. L. (2010). Región turística: Costa Maya. En: B. L. Campos-Cámara (Ed.), Análisis territorial del turismo región Costa Maya (pp. 15-50). México, D.F.: Plaza y Valdés S.A de C.V.

Castillo-Villanueva, L. (2007). Urbanización, turisto y problemas ambientales. En: B. L. Campos-Cámara, L. Castillo-Villanueva \& D. Velázquez-Torres (Eds.), Urbanización y turismo (pp. 67-90). Barcelona: Ediciones Pomares, S.A.

Díaz-Gallegos, J. \& Acosta-Velázquez. (2009). Tendencias en la transformación del uso del suelo y la vegetación aledaña. En: J. Espinoza-Avalos, G. Islebe \& H. Hernández-Arana (Eds.), El sistema ecológico de la bahía de Chetumal / Corozal: costa occidental del Mar Caribe (pp. 225-237). Chetumal: ECOSUR.

Díaz-Gallegos, J. R., Mas, J.-F. \& Velázquez, A. (2010). Trends of tropical deforestation in Southeast Mexico. Singapore Journal of Tropical Geography, 31, 180-196.

Díaz, R. E. C., Bravo, L. C. P., Alatorre, L. C. C. \& Flores, E. S. (2014). Análisis geospacial de la interacción entre el uso de suelo y de agua en el área peri-urbana de Cuasuhteémoc, Chihuahua. Un estudio socioambiental en el norte de México. Investigaciones Geográficas, Boletín del Instituto de Geografia, UNAM, 83, 116-130.

FAO/Unesco. (1988). FAO/Unesco Soil Map of the World,Revised Legend, with corrections and updates, Roma: FAO.

Farley, K. A. (2010). Pathways to forest transition:Local case studies from the Ecuadorian Andes. Journal of Latin American Georgraphy, 9(2), 7-26.

González-Vera, A. (2010). Mahahual, planeación y sustentabilidad. En: Castillo-Villanueva, L., Orozco-Hernández, M. E. \& Velázquez-Torres, D. (Eds.), Ciudades, Urbanización y Metropolización (pp. 359-374). México, D.F.: Plaza y Valdés, S.A. de C.

Hirales-Cota, M. et al. (2010). Agentes de deforestación de manglar en Mahahual-Xcalak, Quintana Roo, sureste de México. Ciencias Marinas, 36(2), 147-159.

Lambin, E. F., Geist, H. \& Lepers, E. (2003). Dynamics of Land-use and Land-cover change in the Tropical Regions. Annu. Rev. Environ. Resour, 28, 205-241.

Lambin, E. F., Geist, H. \& Rindfuss, R. R. (2006). Introduction: Local Processes with Global Impacts. En: E. F. Lambin \& Geist, H. (Eds.), Land-Use and Land-Cover Change: Local Processes and Global Impacts (pp. 1-9). New York: Springer.

López, E., Bocco, G., Mendoza, M. \& Duhau, E. (2001). Predicting land-cover and land-use change in the urban fringe: A case study in Morelia City, Mexico. Landscap and Urban Planning, 55, 271-285. 
Manandhar, R., Odeh, I. O. \& Pontius Jr, R. G. (2010). Analysis of twenty years of categorical land transitions in the Lower Hunterof New South Wales, Australia. Agriculture, Ecosystems and Environment, 135, 336-346.

Jean-François M., Velázquez, A., Díaz-Gallegos, J., Mayorga-Saucedo, R., Alcántara, C., Bocco, G., Castro, R., Fernández, T. \& Pérez-Vega. A. (2004). Assessing land use/cover changes: a nationwide multidate spatial database for Mexico. International Journal of Applied Earth Observation and Geoinformation, 5, 249-261.

Mas, J.-F., Pérez-Vega, A. \& Clarke, K. C. (2012). Assessing simulated land use/cover maps using similarity and fragmentation indices. Ecological Complexity, 11, 38-45.

Mendoza, M., Bocco, G., López-Granados, E. \& Bravo, M. (2010). Hydrological implications of land use and land cover change: Spatial analytical approach atregional scale in the closed basin of the Cuitzeo Lake, Michoacan, Mexico. Singapore Journal of Geography, 31, 197214.

Olson, J. M. et al. (2004). Land Use Change Impacts and Dynamics(LUCID) Project Working Paper\#48. Nairobi: International Livestock Research Institute.

Petit, C., Scudder, T. \& Lambin, E. (2000). Quantifying processes of land-cover change by remote sensing:resettlement and rapid land-cover changes in the southern-easter Zambia. International Journal of Remote Sensing, 22(17), 3435-3456.

PNUMA. (1996). PNUMA:Directrices para una planificación y un manejo integrados de las áreas costeras y marinas en la región del Gran Caribe. Informe Técnico del PAC No. 42, Kingston: Programa Ambiental del Caribe del PNUMA.

Pontius Jr., R. \& Cheuk, M. (2006). A generaliszed cross-tabulation matrix to compare softclasified maps at multiple resolutions. International Journal of Geogrphical Informacion Science, 20(1), 1-30.

Pontius Jr., R. G., Shusas, E. \& McEachern, M. (2004). Detecting important categorical land changes while accounting for persistence. Agriculture, Ecosystems and Environment, 101, 251-268.

Rosado-May, F. J. \& Kissmann, S. (1998). Planning for sustainable tourism in the southern coast of Méxican caribbean. En: L. Hens, R. Borden, S. Suzuki, G. Caravello (Ed.), Research in human ecology: An iterdisciplinary overview (pp. 53-78). Bruselas: VUB University Press.

Teferi, E., Bewket, W., Uhlenbrook, S. \& Wenninger, J. (2013). Understanding recent land use and land cover dynamics in the source region of the Upper Blue Nile, Ethiopia: Spatially explicit statistical modeling of systematic transitions. Agriculture, Ecosystems and Environment, 165, 98-117. 
Teixeira, Z., Heliana, T. \& Marques, J. C. (2014). Systematic processes of land use/land cover change to identify relevant driving forces: Implications on water quality. Science of the Total Environment, 470-471, 1320-1335.

Turner II, B. (2010). Sustainability and forest transitions in southern Yucatán: The land architecture approach. Land Use Policy, 27, 170-179.

Valdez-Lazalde, J. R., Aguirre-Salado, C. A. \& Gregorio, Á.-P. (2011). Análisis de los cambios en el uso del suelo en la cuenca del río metztitlán (México) usando imágenes de satélite: 1985-2007. Revista Chapingo. Serie Ciencias forestales y del ambiente, 17(3), 313-324.

Vázquez-Trejo, A. (2010). La Costa Maya, un espacio para la participación de México en la cooperación ambiental centroamericana. En: B. L. Campos-Cámara (Ed.), Análisis Territorial del Turismo Región Costa Maya (pp. 153-174). México, D.F.: Plaza y Valdés S.A, de C.V.

Velásquez, T. D. (2007). Deforestación de la Selva Maya. Un análisis geográfico regional. Perspectiva Geográfica, 12, 1-21.

Velázquez-Torres, D. \& Castillo-Villanueva, L. (2007). Cancún: turismo y medio ambiente. En: B. L. Campos-Cámara et al. (Eds.), Urbanización y turismo (pp. 52-66). Barcelona: Ediciones Pomares.

Versace, V., Ierodiaconou, D., Stagnitti, F. \& hamilton, A. (2008). Appraisal of random and systematic land cover transitions for regional water balance and revegetation strategies. Agriculture, Ecosystems and Environment, 123, 328-336.

Warner, T. A. \& Campagna, D. (2009). Remote Sensing with IDRISI Taiga: A Beginner's Guide. Hong Kong: Geocarto Interntional Centre.

Recepción: 10 de marzo de 2015

Evaluación:22 de abril de 2015

Aprobación:26 de mayo de 2015 